\title{
The Stability Analysis of Underground Pumping Stations in Complicated Geological Rock Mass
}

\author{
Xiang XU, Zhen-Xing DONG, Wei-Shen ZHU*, Song YU and Yi-Guo XUE \\ Geotechnical and Structural Engineering Research Center, Shandong University, Jinan 250061, \\ China \\ *zhuw@sdu.edu.cn
}

Keyword: Complex geology, Cavern stability, Numerical analysis, Reinforcement, Plastic zone.

\begin{abstract}
Complicated geological conditions and high level ground stress are often encountered with challenges in the construction of underground caverns. It is a key problem to ensure the stability of surrounding rock during construction and operation. The numerical method can be used to simulate and predict the actual situation, to evaluate the feasibility and safety of the excavation and reinforcement scheme, and to provide the optimization suggestion and reduce the engineering risk. An underground pumping station of a water diversion project as a case study, using numerical inversion of in-situ stress, and analysis plastic volume and key points of displacement are conducted and compared under the supporting and no supporting cases, predicting the rock stability during the excavation process and providing some suggestions respectively for engineering design.
\end{abstract}

\section{Introduction}

In recent years, China's water conservancy project underground caverns are emerging, and the stability of the chamber is also affecting the construction safety. The geological structure is often very complicated in the actual formation, which often occurs fault, fold and so on, that is, the complex geological body, which will affect the distribution of the original rock stress distribution and redistribution, thus affecting the safety of underground engineering. At this time how to ensure the stability of the excavation and operation of the cavern is very important. Many scholars and engineers have done a lot of work in this area. After a large number of numerical analysis examples, Zhu[1] fitted out the formula that can predict the displacement of key points and stability of the underground powerhouse with high side wall.

Chen[2] through a large number of prototype monitoring data, studied the displacement characteristics of large underground caverns, the anchor stress characteristics and their change rules. Kong[3] used the finite difference method to analyze the nonlinear elastic-plastic calculation, predicted the dynamic change process of surrounding rock. S. Hibino and M. Motojma[4] used field measurement method to study the deformation law of surrounding rock in ten more large hydropower plants in Japan. In this paper, the stability of surrounding rock of underground pumping station of a diversion project is studied. Based on the measured in-situ stress data, the numerical method is used to achieve inversion of initial in-situ stress and to simulate the different excavation support schemes, and the stability of underground pumping station under different working conditions is calculated and analyzed.

\section{Engineering Survey}

The depth of pumping station is about 170 195m. That project is composed of the power house, into the pool and the water outlet chamber, and they are arranged in parallel, the axial direction and the maximum horizontal principal stress direction is closed. The excavation size of power house is $120.8 \mathrm{~m} * 21.3 \mathrm{~m} * 41.6 \mathrm{~m}$ (length * width * height), and 7 sets of centrifugal pump are installed; the distance between the center line of water outlet valve and pump house is of $36.7 \mathrm{~m}$, and the size of latter is $98.8 \mathrm{~m} * 6.5 \mathrm{~m} * 16.5 \mathrm{~m}$ (length * width * height); the inlet water tank size is $130 \mathrm{~m} * 10 \mathrm{~m} *$ $10.5 \mathrm{~m}$ (length $*$ width $*$ height). 
The main surrounding rock (limestone) of the underground pumping station system is type III in classification and marl exists partly, which is type IV in classification. In the main powerhouse, the type III surrounding rock posses about $80 \%$, while the rest is type IV. In underground pumping station is mainly composed of layered rock strata, weak interlayer exists in the middle like sandwich, and the Fa1 as normal fault passes through the south side of the site, which is $110 \mathrm{~m}$ from the side wall of pump station in distance. Three groups of fractures are mainly developed in the rock mass.

\section{Numerical Calculation and Analysis}

To genenrate the elements, ANSYS is used to simulate the stratum and surrounding rock. The simulation scope includes the main power house, the inlet water tank and the water outlet valve chamber as well as the grouting corridor and the traffic tunnel, at the same time, the fault Fa1 is also considered which has great influence to the stability of the cavern group. Stratigraphic block is divided into a total of 4744678 units, 83177 nodes. The sketch map of 3D stratum is shown in Figure 1. Displacement boundary conditions are used in the calculation model, and the constitutive relation of the computational model is M-C. Firstly, according to the terrain, geological, in-situ stress measurement points and measured data in the calculation domain, the FLAC3D and regression analysis procedure are used to carry on the in-situ stress inversion[5]. After three dimensional ground stress field fitting, the calculated value and the measured value are very close with each other, the complex correlation coefficient $\mathrm{R}$ is more than 0.9 , and the axial lateral pressure coefficient is $\mathrm{k}_{0}=2.42$, while the lateral one is of 1.27 . Then numerical simulation of caverns excavation and for case of reinforcement are carried out. The mechanical parameters of surrounding rock of underground powerhouse are shown in Table 1.

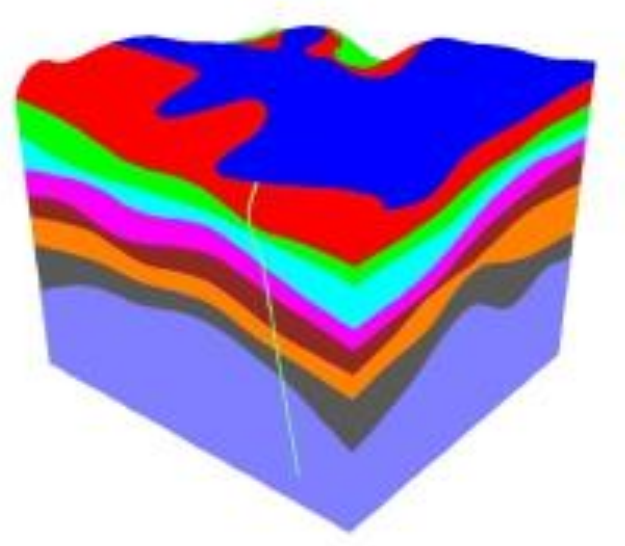

Fig.1 The sketch map of 3D stratum

Table 1 The mechanical parameters of rock mass

\begin{tabular}{cccccccc}
\hline No & $\begin{array}{c}\text { surrounding } \\
\text { rock } \\
\text { classificatio } \\
\mathrm{n}\end{array}$ & $\begin{array}{c}\text { densit } \\
\mathrm{y} \\
\left(\mathrm{g} / \mathrm{cm}^{3}\right. \\
)\end{array}$ & $\begin{array}{c}\text { elasticit } \\
\mathrm{y} \\
\text { modulu } \\
\mathrm{s}(\mathrm{GPa})\end{array}$ & $\begin{array}{c}\text { frictio } \\
\mathrm{n} \\
\text { angle } \\
\left({ }^{\circ}\right)\end{array}$ & $\begin{array}{c}\text { cohesio } \\
\mathrm{n}(\mathrm{MPa})\end{array}$ & $\begin{array}{c}\text { poisson } \\
\text { s ration }\end{array}$ & $\begin{array}{c}\text { tensile } \\
\text { strengt } \\
\mathrm{h} \\
(\mathrm{MPa})\end{array}$ \\
\hline 1 & $\mathrm{~V}$ & 2.58 & 0.6 & 37 & 0.37 & 0.4 & 0.3 \\
\hline 2 & IV & 2.58 & 0.7 & 47.2 & 0.43 & 0.33 & 0.6 \\
\hline 3 & III & 2.68 & 5 & 45.3 & 0.95 & 0.22 & 1.1 \\
\hline 4 & IV & 2.49 & 0.7 & 46 & 0.25 & 0.25 & 0.55 \\
\hline 5 & III & 2.7 & 5 & 45.3 & 0.82 & 0.22 & 0.9 \\
\hline 6 & III & 2.69 & 5 & 45.3 & 0.95 & 0.22 & 1.1 \\
\hline
\end{tabular}


During the excavation of large underground powerhouse, the bolts and anchor cables are widely used as the main support methods. In the software FLAC3D, the anchor bolt and anchor cable are simplified as the anchor cable unit to deal with. But this kind of simulation method cannot fully reflect the supporting effect of bolt. Many experimental results show that the anchorage of rock mass its strength and stiffness increasing effect are much larger than the anchoring force to the surrounding rock stress as a additional effect, in particular, the stiffness and strength parameters of the reinforced rock mass can be greatly improved. In this paper, this kind of the additional equivalent reinforcement effect of the rock bolt to the surrounding rock mass is taken into account , and the mechanical parameters of the anchoraged rock will be increased. The new equivalent supporting effect analysis of the strength of surrounding rock can be expressed by the following formula[6]:

$$
\left\{\begin{array}{l}
c_{1}=c_{0}+\eta \frac{\tau_{s} s}{a_{i} b}=c_{0}+\Delta c \\
\varphi_{1}=\varphi_{0}
\end{array}\right.
$$

In which, ${ }^{c}{ }_{0}, \varphi_{0},{ }_{1}$ are the cohesion and internal friction angle of the original rock mass and rock after anchor respectively; $\tau$-shear strength of rock bolts; s-cross section area of anchor bolt; $a, b-$ longitudinal and transverse spacings of anchor bolts; $\eta$-dimensionless coefficient, concerned with arrangement characteristic of anchor group.

In this paper, a quasi 3D model of an unit turbin is used to study and to design the supporting parameters of surrounding rock of underground powerhouse. The plastic zone volume and the displacement of key points under two working conditions are calculated, which is under adding bolt support while the other is of no bolting case. The support scheme is: The main building: top arch system bolts, $\Phi 28 \mathrm{~mm}, \mathrm{~L}=6 / 9 \mathrm{~m}, @ 1.5 * 1.5 \mathrm{~m}$, the side wall part 1 (from the lower part of the top arch to the crane beam) system bolts: $\Phi 28 \mathrm{~mm}: \mathrm{L}=9 \mathrm{~m}$, @ $1.5 * 1.5 \mathrm{~m}$, the side wall part 2 (the lower side wall below crane beam) system bolt: $\Phi 25 \mathrm{~mm}, \mathrm{~L}=5 / 7 \mathrm{~m}$, @ $1.5 * 1.5 \mathrm{~m}$; the water outlet valve chamber system bolt: $\Phi 22 \mathrm{~mm}, \mathrm{~L}=4 \mathrm{~m}$, @ $1.5 * 1.5 \mathrm{~m}$; suction sump system bolt: $25 \mathrm{~mm}, \mathrm{~L}=$ 4.5m, @1.5*1.5m.

The location of key points and the anchor position are shown in Figure 2, the key points c11, $\mathrm{c} 12, \mathrm{c} 23, \mathrm{c} 24, \mathrm{c} 25, \mathrm{c} 26, \mathrm{c} 33$, and c34 are for the side wall of the cavern. The comparison of the plastic zone of two conditions are shown in Table 2, and the plastic zone distribution are shown in Figure 3,4.

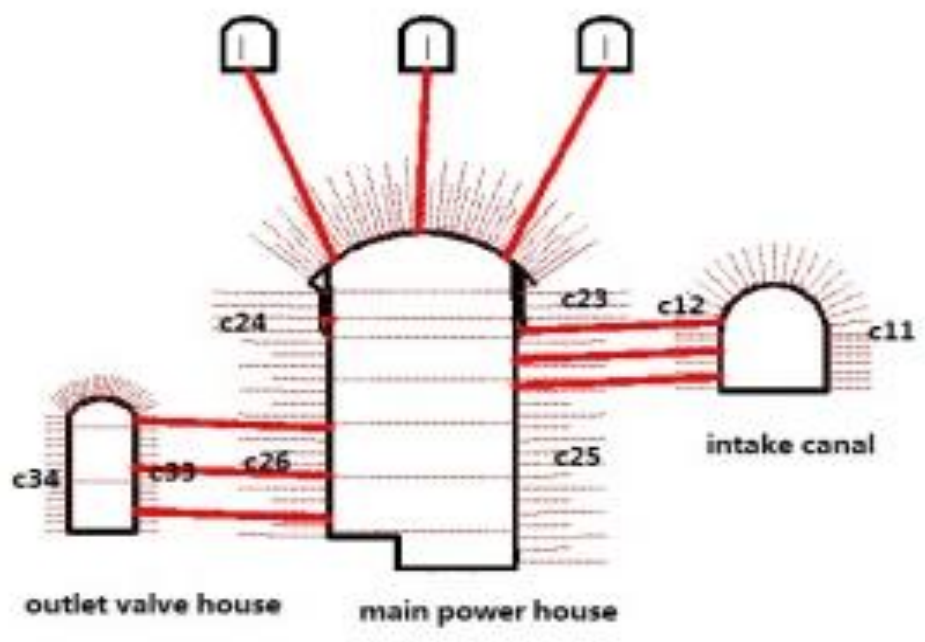

Fig.2 Arrangement of anchor bolt and key points of displacement position 
Table 2 The comparison of the plastic zone of two conditions

\begin{tabular}{ccc}
\hline & no anchor & $\begin{array}{c}\text { anchor bolt and } \\
\text { decreases percent } \\
\left(\mathrm{m}^{3}\right)\end{array}$ \\
\hline The total volume & 7554.14 & $6570.49 /-13.02 \%$ \\
\hline main power house & 5603.99 & $4938.81 /-11.87 \%$ \\
\hline suction sump & 1601.59 & $1388.36 /-13.31 \%$ \\
\hline outlet valve chamber & 348.56 & $243.32 /-30.2 \%$ \\
\hline
\end{tabular}
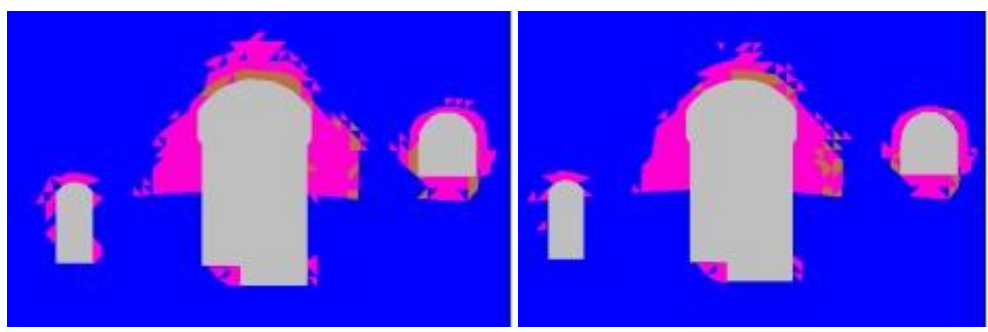

Fig. 3 The plastic zone of on bolt case

Fig.4 The plastic zone of anchor bolt case

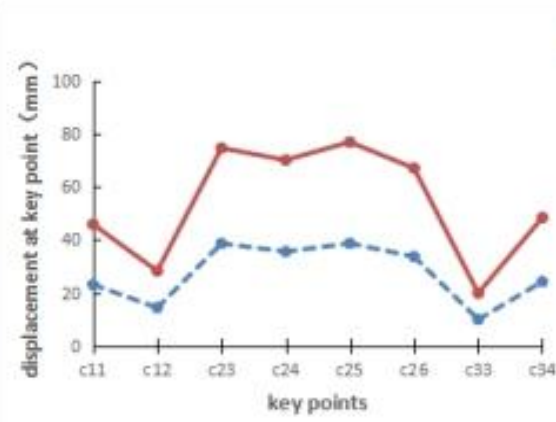

Figure 5 typical point displacement curve of two conditions

The figure 3,4 show that the mostly damage of surrounding rock is shear failure, and a few parts are local tensile failure. After the bolt support, the damage area of the rock mass is significantly reduced, and the failure zone of the arch angle of the upper side wall and the middle rock mass of downstream side wall disappeared are obviously decreased. The total volume of the plastic zone is decreased by $13.03 \%$ compared with the excavation of no bolt case, specially the plastic zone of water outlet valve chamber is reduced by $30.2 \%$, which shows that the stability of the surrounding rock is improved greatly after the anchorage support. At the same time, the deformation of the side wall is generally larger, but the displacement of the key points is greatly reduced after the anchor bolt arranged, which is shown in Figure 5.

\section{Conclusions}

(1)The surrounding rock of underground pump station is layered obviously and lithology is complex, and there are weak intercalations. The damage zone of surrounding rock in the upper part of the chamber is larger, while the lower rock lithology is better, and the contrast between upper and lower level parts is obvious.

(2) Around the free surface of the cavity, the vault and the displacement of high side wall of the cavern with weak interlayer are the largest. It is better to reduce the damage of the surrounding area and the side wall deformation side support way, and the effect is more obvious after using the formula to enhance the anchoring effect. 
(3)The anchorage support has a good effect on restraining the deformation of the cavern and improving the stability of the cavern, and ensuring the safety of the project.

\section{Acknowledgements}

The work is supported by the National Natural Science Foundation of China 51579140. W.S. Zhu is the corresponding author.

\section{References}

[1] W.S. Zhu, study on prediction of high wall displacement and stability judging method of surrounding rock for large cavern groups. Chinese Journal of Rock Mechanics and Engineering $[\mathrm{J}], 2007$.

[2] Chen Zhong xian, Rock displacement and load of bolts around large scale cavities with high stress. Chinese Journal of Geotechnical Engineering[J],2000(5).

[3] Kong Xiang fu, Study on stability of underground power house of a hydropower station some station. Rock and Soil Mechanics[J],2006(10).

[4] S. Hibino, M. Motojma, Anisotropic behavior of jointed rock mass

[5] around large-scale caverns[C]// Proc. of the 9th Int. Conference on

[6] Rock Mech.. Paris: [s.n.],1999: 385-388.

[7] GUO Yun-hua, Improved regression method for initial geostress based on FLAC3D. Chinese Journal of Geotechnical Engineering[J],2014(5).

[8] ZHU W, ZHANG Y. Effect of Supporting Rocks by Bolts and Its Application to High Slope of Three Gorges Flight Lock [A].Proceedings of International Symposium on Anchoring and Grouting Techniques[C]. Guangzhou, 1994: 188-196. 